\title{
UM PERFIL DOS PROFESSORES QUE COMPARTILHAM EXPERIÊNCIAS DE EDUCAÇÃO MATEMÁTICA COM ESTUDANTES DA EDUCAÇÃO PROFISSIONAL E TECNOLÓGICA
}

\author{
A PROFILE OF TEACHERS SHARING EXPERIENCES IN MATHEMATICS \\ EDUCATION WITH STUDENTS OF TECHNICAL AND VOCATIONAL EDUCATION \\ AND TRAINING
}

Deborah da Silva Pimentel ${ }^{1}$; Ana Clara Frossard Souza ${ }^{2}$, Lauro Chagas e Sá ${ }^{3}$

\begin{abstract}
RESUMO
Este manuscrito parte de uma inquietação dos autores sobre características da formação e da atuação profissional de professores que compartilham experiências de Educação Matemática com alunos de cursos técnicos em diferentes eventos acadêmicos. O artigo é, nesse sentido, um desdobramento de um projeto de Iniciação Tecnológica que instituiu o Repositório de Experiências de Educação Matemática na Educação Profissional (REMEP). Nessa pesquisa, objetivamos compreender possíveis traços característicos no perfil dos professores que atuam e ensinam matemática na Educação Profissional e Tecnológica. A estratégia metodológica consistiu em analisar a formação dos docentes, seus vínculos empregatícios, suas experiências com pesquisas de Educação Matemática na Educação Profissional Técnica de Nível Médio e suas participações em grupos de pesquisa. O levantamento de dados trouxe resultados otimistas no que tange à participação na busca de um ensino interdisciplinar e a importância da integração entre a Matemática e as demais disciplinas para a emancipação do aluno. Com essa pesquisa, observamos que a preocupação em relação ao ensino profissionalizante está cada vez mais presente no cotidiano de docentes das mais diversas áreas do conhecimento, o que nos permite ampliar a noção de "professores que ensinam matemática" até então associada aos matemáticos e pedagogos.
\end{abstract}

Palavras-chave: Educação Matemática, Educação Profissional e Tecnológica, Integração Curricular, Formação de professores.

\footnotetext{
${ }^{1}$ Licencianda em Química pelo Instituto Federal do Espírito Santo (Ifes), Vila Velha, Espírito Santo, Brasil. Endereço para correspondência: Avenida Ministro Salgado Filho, n. 1.000, Bairro Soteco, Vila Velha, Espírito Santo, Brasil, CEP: 29106-010. E-mail: deborahpimentel@ gmail.com.

(iD) ORCID iD: https://orcid.org/0000-0003-0178-4655.

${ }^{2}$ Licencianda em Química pelo Instituto Federal do Espírito Santo (Ifes), Vila Velha, Espírito Santo, Brasil. Endereço para correspondência: Avenida Ministro Salgado Filho, n. 1.000, Bairro Soteco, Vila Velha, Espírito Santo, Brasil, CEP: 29106-010. E-mail: acfrossards@gmail.com.

(D) ORCID iD: https://orcid.org/0000-0003-0433-7973.

${ }^{3}$ Doutor em Ensino de Matemática pela Universidade Federal do Rio de Janeiro (UFRJ). Professor do Instituto Federal do Espírito Santo (Ifes), Vila Velha, Espírito Santo, Brasil. Endereço para correspondência: Avenida Ministro Salgado Filho, n. 1.000, Bairro Soteco, Vila Velha, Espírito Santo, Brasil, CEP: 29106-010. E-mail: lauro.sa@ifes.edu.br.
}

(iD) ORCID iD: https://orcid.org/0000-0003-1820-4856. 
Deborah da Silva Pimentel, Ana Clara Frossard Souza e Lauro Chagas e Sá

Um perfil dos professores que compartilham experiências de Educação Matemática com estudantes da Educação Profissional e Tecnológica

ABSTRACT

This manuscript stems from the authors' concerns about the characteristics of the formation and professional performance of teachers who share experiences in Mathematics Education with students from technical courses in different academic events. In this sense, the article is an offshoot of a Technological Initiation project that established the Repository of Experiences in Mathematics Education in Professional Education (REMEP). In this research, we aim to understand possible characteristic features in the profile of teachers who work and teach mathematics in Technical and Vocational Education and Training. The methodological strategy consisted of analyzing the training of teachers, their employment relationships, their experiences with research in Mathematics Education in TVET and their participation in research groups. The data collection brought optimistic results regarding participation in the search for interdisciplinary teaching and the importance of integration between Mathematics and other disciplines for the student's emancipation. With this research, we observe that the concern regarding professionalizing education is increasingly present in the daily lives of teachers from the most diverse areas of knowledge, which allows us to expand the notion of "teachers who teach mathematics" until then associated with mathematicians and pedagogues.

Keywords: Mathematical Education, Professional and Technological Education, Curricular Integration, Teacher Training. 


\section{Introdução}

Percebemos que a quantidade de pessoas que concluem o Ensino Médio fica abaixo do estabelecido pelo Plano Nacional de Educação (PNE). Segundo uma pesquisa do Instituto Brasileiro de Geografia e Estatística (IBGE) de 2017, da quantidade total de pessoas que concluíram o ensino médio nesse ano, 67,7\% frequentaram apenas a rede pública e $28,2 \%$ apenas a rede privada. Ao analisar essa informação, vimos que $35,9 \%$ dos estudantes pertencentes ao primeiro grupo ingressaram no ensino superior, enquanto o número atingiu a marca 79,2\% para os estudantes do segundo grupo (BRASIL, 2017). Dessa forma, o mundo do trabalho se apresenta como única alternativa para a maior parte dos estudantes egressos no ensino médio.

A formação de trabalhadores no Brasil inicia-se junto com sua colonização. Desde os tempos mais remotos do país já se fazia presente os aprendizes de ofícios, mas somente em 1906, o então Presidente da República Nilo Peçanha inicia a Educação Profissional e Tecnológica (EPT), criando dezenove "Escolas de Aprendizes Artífices" (BRASIL, 2009). Mesmo sendo uma modalidade de ensino centenária, ainda se discute uma necessidade na articulação do ensino básico com o núcleo profissionalizante devido às exigências com relação ao mundo do trabalho.

Apesar do discurso para a formação de cidadãos emancipados, ou seja, uma educação não somente voltada para o mercado de trabalho, mas também para o crescimento pessoal do sujeito, concordamos com Moura (2014, p. 95) quando afirma que

Não há conteúdo que viabilize o diálogo. Cada ciência/disciplina está restrita
ao seu espaço, porque os professores são formados a partir dessa racionalidade
acentuadamente disciplinar, apesar dos discursos voltados para a multi e a
interdisciplinaridade serem intensos.

Quando visto dessa maneira, compreendemos que o professor só exerce seu papel dentro da sua área. Entretanto, apenas esse conhecimento específico não é suficiente para o exercício da docência no campo da EPT, uma vez que nos deparamos com professores de formações diversas que ensinam em disciplinas específicas dos núcleos profissionalizantes.

Conforme descrito na Resolução no 6/2012 do Conselho Nacional de Educação (CNE), o ensino na EPT deve ser promovido de forma contextualizada para que haja integração entre a teoria apresentada em sala de aula e a vivência do aluno no âmbito profissional. Nesse sentido, torna-se necessário promover uma articulação entre os 
Deborah da Silva Pimentel, Ana Clara Frossard Souza e Lauro Chagas e Sá

Um perfil dos professores que compartilham experiências de Educação Matemática com estudantes da Educação Profissional e Tecnológica

conteúdos estudados para que o ensino se torne verdadeiramente integrado e não somente uma sobreposição de componentes curriculares.

Nesse contexto, o presente artigo parte de uma pesquisa do Programa Institucional de Iniciação em Desenvolvimento Tecnológico e Inovação (PIBITI ${ }^{4}$ ), desenvolvida no EMEP - Grupo de Pesquisa em Educação Matemática e Educação Profissional, em $2019^{5}$. Assim, objetiva compreender possíveis traços característicos no perfil dos professores que atuam e ensinam matemática na Educação Profissional. Para tanto, metodologicamente, analisamos as formações e os campos de atuação dos professores que compartilham experiências de Educação Matemática com alunos de cursos técnicos em edições do Encontro Nacional de Educação Matemática (ENEM) e da Feira Nacional de Matemática (FMat). Dessa forma, esperamos contribuir com pesquisas acerca da Formação de Professores discutindo a respeito das características da formação e da atuação profissional de professores que ensinam Matemática na EPT.

Neste artigo, iniciamos o debate explicando a integração curricular necessária para a EPT e o papel da Matemática nesse processo. Em seguida, explicamos a metodologia usada para a coleta e análise dos dados. Depois, debatemos os resultados obtidos e, por fim, fazemos algumas considerações.

\section{Integração curricular no ensino de Matemática e formação dos professores da}

\section{Educação Profissional e Tecnológica}

Em virtude da expansão de novos meios de produção, o conhecimento foi fragmentado. A fim de diminuir esse distanciamento, criou-se o conceito de "Currículo Integrado" para promover a interdisciplinaridade, tendo como objetivo alcançar o conhecimento a partir do viés de uma visão global. Quando se trada da Educação Profissionalizante, o foco é que a educação básica se torne parte inseparável da Educação Profissional e vice-versa (FRIGOTTO; CIAVATTA; RAMOS, 2005).

\footnotetext{
${ }^{4}$ O projeto foi cadastrado na Pró-Reitoria de Pesquisa do Instituto Federal do Espírito Santo sob código PJ00005125 e contou com financiamento do Conselho Nacional de Desenvolvimento Científico e Tecnológico $(\mathrm{CNPq})$, da Fundação de Amparo à Pesquisa e Inovação do Espírito Santo (Fapes) e do Instituto Federal do Espírito Santo (Ifes).

5 O EMEP reúne professores-pesquisadores do Instituto Federal do Espírito Santo, da Secretaria de Educação do Espírito Santo e de instituições privadas que investigam práticas de Educação Matemática nas etapas de Ensino Médio e de Ensino Superior, bem como na modalidade de Educação Profissional e Tecnológica. Para conhecer mais informações sobre o grupo, acesse https://emep.ifes.edu.br
} 
Ao encontrarmos uma realidade complexa e em constante transformação entre o ensino científico e o mundo do trabalho, observa-se a importância da integração do ensino na Educação Profissional e Tecnológica, que tem como objetivo superar a dicotomia ainda presente no sistema tradicional de ensino. A busca pela integração curricular não está condicionada a esquecer as peculiaridades de cada disciplina, mas sim que seja uma equivalência entre o ensino e o mundo do trabalho. Desse modo leva-se em consideração o conhecimento e as vivências trazidas por cada estudante, tornando esse ensino significativo e compreensivo em seu aprendizado.

Integrar o currículo escolar é “[...] condição necessária para a travessia em direção ao ensino médio politécnico e à superação da dualidade educacional pela superação da dualidade de classes" (FRIGOTTO; CIAVATTA; RAMOS, 2005, p. 45), além de também consolidar o papel social da escola. Ao reforçar o distanciamento entre as disciplinas escolares e científicas, limita-se o conhecimento do aluno para uma forma simplificada, impedindo a sua visão crítica. Alinhados a essa discussão, apresenta-se então um ensino interdisciplinar como forma de solucionar a fragmentação do conhecimento. Paviani (2004, p. 17) ressalta que

\footnotetext{
Para alcançar seus objetivos, ela [interdisciplinaridade] não pode ser deduzida a uma simples colaboração ou intercâmbio entre pesquisadores e professores. Ela envolve desde os aspectos lógicos e epistemológicos do conhecimento até a aplicação de conhecimento de uma disciplina em outra. Sua missão é a de conservar e mediar as contradições do conhecimento nas esferas pedagógicoepistemológicas e políticas socioinstitucionais.
}

Ao falar sobre Matemática, Bittencourt (2009) traz uma abordagem a respeito do duplo aspecto que essa ciência possui: seu uso como instrumento para outras ciências e um conjunto específico de saberes. Curiosamente, apesar da integração estar presente até na característica dessa disciplina, ainda há dificuldades na implementação dessas propostas, mantendo a organização disciplinar dos conteúdos trabalhados em sala de aula. Nesse sentido, a autora busca compreender as dificuldades dessa implementação e porque elas não foram geradas no cotidiano escolar.

Quando falamos a respeito do docente de Educação Profissional e Tecnológica, levamos em consideração que seus saberes devem ir além dos didáticos, para que seja possível inserir o estudante com êxito no seu futuro exercício profissional. Mesmo que esse discurso seja constante, ainda se têm a necessidade de apontar as possibilidades que permeiam essa articulação. Concordamos com Fernandes e Valente (2019) quando os 
Deborah da Silva Pimentel, Ana Clara Frossard Souza e Lauro Chagas e Sá

Um perfil dos professores que compartilham experiências de Educação Matemática com estudantes da Educação Profissional e Tecnológica

autores afirmam que é necessário assumirmos uma responsabilidade epistemológica, o que implica em "reivindicarmos espaços e reconhecimento como sujeitos qualificados para a proposição, gestão e atuação nas políticas educacionais voltadas à habilitação daqueles que ensinam Matemática (FERNANDES; VALENTE, 2019, p. 9).

Silva e Oliveira (2018) abordam algumas experiências docentes no Ensino Médio Integrado no estado do Ceará. Ao entrevistar alguns professores de uma escola, os pesquisadores constataram que as disciplinas profissionalizantes são ministradas por um corpo docente de formação técnica e as disciplinas propedêuticas por um outro corpo docente, geralmente com licenciatura. Porém, no cotidiano, observamos que esses dois grupos não estão isolados. Assim, para que haja melhor compreensão e atuação futura do aluno, os conteúdos do curso técnico precisam estar integrados sempre que possível. Dando continuidade a esse debate, Freitas e Sá (2020) investigaram os fatores que influenciam no planejamento de professores que ensinam Matemática na Educação Profissional e Tecnológica.

As reflexões de Silva e Oliveira (2018) e Freitas e Sá (2020) revelaram que existem professores que lecionam matemática, seja em disciplinas básicas ou aplicadas ao curso técnico, os quais não possuem formação inicial na área, ainda que alguns se identifiquem com a Educação Matemática.

\footnotetext{
Em nosso estudo, adotamos a nomenclatura "Professores que ensinam Matemática" visto que os professores da Educação Profissional podem ter formações diversas para atuarem em disciplinas do núcleo profissionalizante, como o Arquiteto ou Engenheiro Civil que leciona Desenho Técnico, o Administrador que ensina Matemática Financeira e o Engenheiro de Produção que atua com Estatística (FREITAS; SÁ, 2020, p. 14)
}

Nesse contexto, essa pesquisa dá continuidade aos apontamentos de Freitas e Sá (2020), no sentido de evidenciar que esses profissionais também integram a comunidade de educadores matemáticos, apresentando trabalhos em eventos acadêmicos, como o ENEM e a FMat.

\section{Metodologia}

Conforme anunciado anteriormente, esse trabalho pretende compreender o perfil dos professores que compartilham experiências de Educação Matemática na Educação Profissional e Tecnológica (EPT). Para tanto, apresenta os dados de trabalhos nos ENEM e nas FMat, presentes no Repositório de Experiências de Educação Matemática na 
Deborah da Silva Pimentel, Ana Clara Frossard Souza e Lauro Chagas e Sá

Um perfil dos professores que compartilham experiências de Educação Matemática com estudantes da Educação Profissional e Tecnológica

Educação Profissional (REMEP) - portal desenvolvido pelo grupo EMEP que congrega experiências na Educação Matemática apresentados a partir de 2010, quando foi instituída a Rede Federal do Educação Profissional e Tecnológica.

Na ocasião da construção do REMEP, o método para o levantamento de dados compreendeu um protocolo de seleção e análise dos trabalhos apresentados nos referidos eventos. Para construção da amostra da pesquisa, mapeamos os trabalhos publicados nas quatro últimas edições dos Encontros Nacionais de Educação Matemática e nas cinco edições mais recentes das Feiras Nacionais de Matemática. Estas edições foram selecionadas a partir do recorte temporal 2010-2020, que marca a primeira década dos Institutos Federais brasileiros.

Os textos incluídos no repositório ou estavam na categoria Ensino Médio das FMat ou, no caso do ENEM, continham no título ou no corpo do trabalho as palavras "técnica", "técnico" ou "profissional". Depois dessa inserção, realizamos uma nova conferência, quando foram excluídos os projetos da FMat oriundos de escolas não tinham Ensino Profissional e textos do ENEM que não possuíam uma proposta pedagógica. Com esse protocolo, na FMat partimos de 601 trabalhos e chegamos em 62 e, no ENEM, saímos de 6094 trabalhos e chegamos em 83. Dessa forma, totalizamos 145 textos que posteriormente foram indexados e inseridos no repositório.

Os trabalhos que compõem o REMEP foram originados de 22 dos 27 estados do Brasil, compreendendo toda as regiões do país. De acordo com o mapa a seguir, Acre, Minas Gerais e Rio Grande do Sul são os estados com o maior índice de artigos analisados. 
Imagem 1 - Quantidade de trabalho por estado

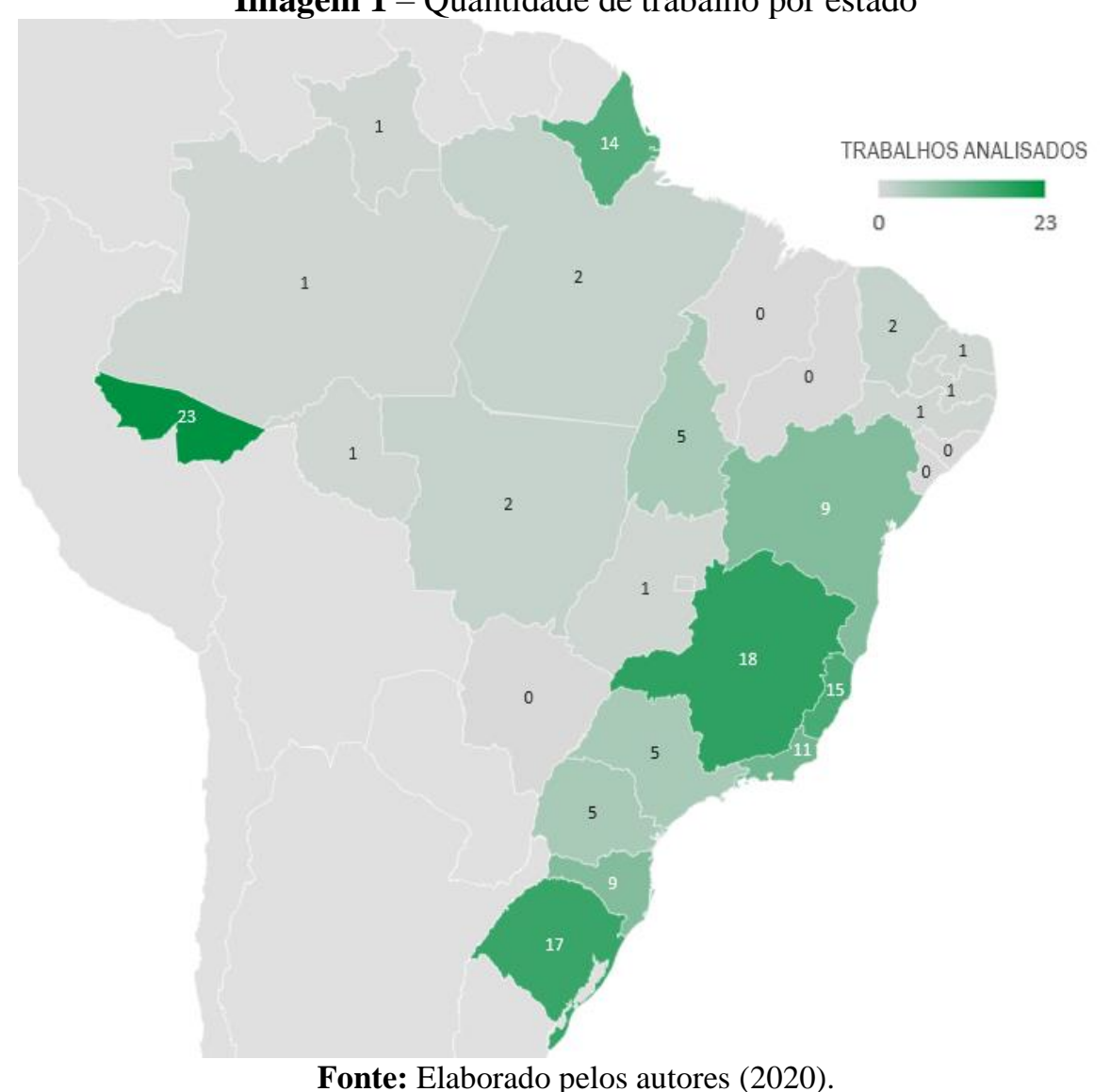

Fonte: Elaborado pelos autores (2020).

Depois de selecionados, os trabalhos foram analisados a partir de uma ficha de descritores - formulário do Google com perguntas sobre os autores, as escolas, os cursos, as experiências e a estrutura dos artigos. No caso dos projetos de FMat, escritos por estudantes sob supervisão de um orientador, analisou-se informações profissionais do docente envolvido no projeto; nos textos do ENEM, considerou-se informações dos primeiros autores. Algumas das informações levantadas durante o fichamento ficaram disponíveis para consulta no REMEP, de modo a facilitar a identificação dos artigos pelos usuários do repositório.

Para a pesquisa que culminou neste artigo, analisamos parte da planilha gerada pelo fichamento dos 145 textos. Neste sentido, investigamos quatro dados principais: formação dos autores, seus vínculos empregatícios, suas experiências com pesquisas de Educação Matemática na Educação Profissional Técnica de Nível Médio (EPTNM) e suas participações em grupos de pesquisa.

De acordo com uma leitura prévia do Currículo Lattes de cada autor/orientador, tentamos identificar se o docente já havia apresentado alguma experiência de Educação 
Deborah da Silva Pimentel, Ana Clara Frossard Souza e Lauro Chagas e Sá

Um perfil dos professores que compartilham experiências de Educação Matemática com estudantes da Educação Profissional e Tecnológica

Matemática na EPTNM ou se a experiência analisada era a primeira nessa perspectiva. Como alguns currículos não estavam atualizados há mais de um ano, ressalvamos que eventualmente as interpretações podem não refletir o perfil exato de algum dos professores. Inspirados na pesquisa de Ferreira (2016), também realizamos levantamento da participação em grupos de pesquisa, recorrendo ao Diretório de Grupos de Pesquisa do Conselho Nacional de Desenvolvimento Científico e Tecnológico (DGP-CNPq).

\section{O perfil profissional do docente que ensina Matemática na EPT}

No que tange seu vínculo empregatício ou acadêmico, $75 \%$ dos docentes eram pertencentes aos Institutos Federais, $15 \%$ às redes de ensino privado e/ou escolas confessionais e $10 \%$ às Universidades Federais e/ou Estaduais. A ampla porcentagem de profissionais atuantes em Institutos Federais, atingindo uma marca de 109 no total analisado, pode ser explicada pela capilaridade a abrangência dessa rede de ensino, conforme descrito na sua lei de criação:

\footnotetext{
Os Institutos Federais são instituições de educação superior, básica e profissional, pluricurriculares e multicampi, especializados na oferta de Educação Profissional e tecnológica nas diferentes modalidades de ensino, com base na conjugação de conhecimentos técnicos e tecnológicos com as práticas pedagógicas, nos termos desta Lei (BRASIL, 2008, art. $2^{\circ}$ ).
}

A respeito da formação acadêmica desses autores, classificamos segundo Moura (2014), em quatro grupos distintos: a) os profissionais não graduados, muito comumente presentes em rede de ensino privado, são pessoas que já atuaram ou ainda trabalham na área técnica, cujo único foco é preparar uma mão de obra treinada para realizar com eficiência as atividades de sua profissão; b) os bacharéis, mas não licenciados, são os docentes que possuem formação e plena compreensão do mundo do trabalho e das técnicas que envolvem sua profissão, como por exemplo, engenheiros, arquitetos, administradores e outros bacharéis que exercem a docência, mas sem uma formação pedagógica; c) os licenciados em disciplinas da educação básica, que são formados para o exercício da docência nesse âmbito, ou seja, para atuarem no ensino fundamental e médio; d) os que ainda se formarão, é o grupo que abriga os alunos que ainda estão na graduação de licenciatura e os futuros profissionais que ainda começarão a formação superior nessa área. 
Deborah da Silva Pimentel, Ana Clara Frossard Souza e Lauro Chagas e Sá

Um perfil dos professores que compartilham experiências de Educação Matemática com estudantes da Educação Profissional e Tecnológica

O Gráfico 1 apresenta a estatística presente na amostra analisada de acordo com as classificações do autor. O bloco do formulário em análise foi preenchido levando em consideração apenas o primeiro autor de cada artigo analisado, no ENEM, e o professor orientador, na FMat.

Gráfico 1 - Formação dos docentes na Educação Profissional e Tecnológica

\section{Formação dos docentes na Educação Profissional e Tecnológica}

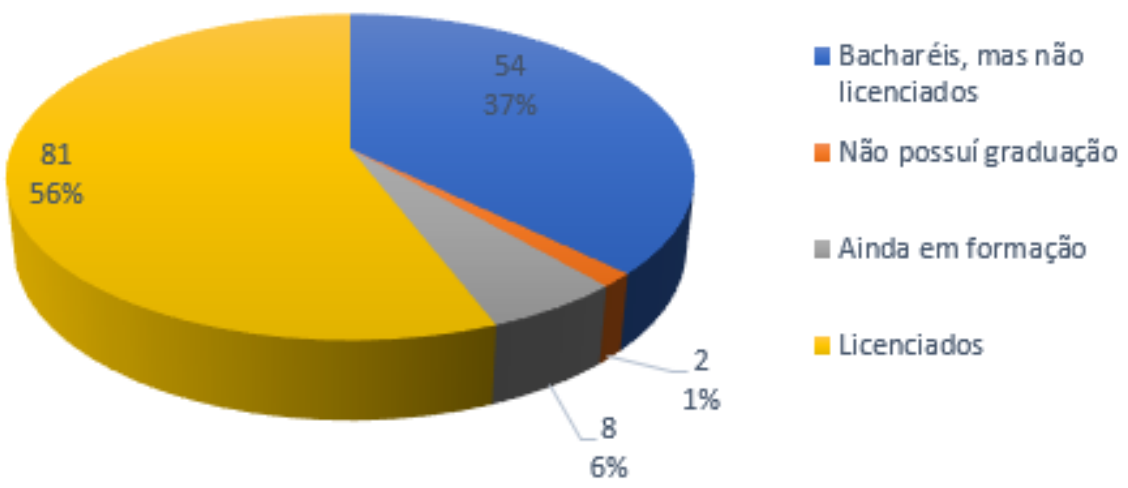

Fonte: Elaborado pelos autores, 2020.

No cenário exposto, concluímos que a quantidade de professores licenciados ainda prevalece sobre os demais grupos. A quantidade de bacharéis não licenciados em Matemática também se destaca sobre os demais, representando mais que um terço da amostra. Conforme apontado por Freitas e Sá (2020), são profissionais formados em diversos cursos e que ainda assim ministram aulas com conteúdo matemático, ou seja, são professores que ensinam matemática, como por exemplo o Engenheiro de Produção que ensina Geometria Espacial, a Arquiteta que ensina Projeção Ortogonal e até o Químico que leciona Estatística para seus alunos, esses são exemplos existentes entre os trabalhos analisados. De acordo com Machado (2008), independente da área de formação, dentro da sala de aula o professor deve inserir em sua prática educativa o contexto social vivenciado, explorando situações-problema que dialoguem com diferentes campos de conhecimento.

Diante do perfil apresentado, nos interessou identificar as experiências acadêmicas relacionadas ao ensino técnico. De acordo com análise dos Currículos Lattes dos autores, verificamos que $39 \%$ dos autores possuíam outras experiências de Educação 
Deborah da Silva Pimentel, Ana Clara Frossard Souza e Lauro Chagas e Sá

Um perfil dos professores que compartilham experiências de Educação Matemática com estudantes da Educação Profissional e Tecnológica

Matemática na EPTNM listada em seus currículos. A maior parte, 61\%, tinha apenas o trabalho analisado como experiência. Continuar pesquisando a respeito da EPT garante que as especificidades do docente da Educação Profissional sejam alcançadas. Essas características são citadas por Araújo (2008) como sendo:

[...] o conteúdo capaz de instrumentalizar o exercício profissional. A formação do docente da Educação Profissional deve garantir a articulação dos saberes técnicos específicos de cada área, dos saberes didáticos e do saber do pesquisador (ARAÚJO, 2008, p. 58).

Entende-se que um assunto passa a ser disseminado com mais frequência quando compartilhado. Os grupos de pesquisa são espaços ideais para essa troca de conhecimentos, contribuindo para a qualificação de seus integrantes. Nesse contexto, ao analisar os dados vimos que 53\% destes docentes participam de algum grupo de pesquisa, segundo o DGP-CNPq. Os valores obtidos a respeito dos grupos de pesquisa são referentes à análise feita com os dados do ENEM, uma vez que tivemos problemas técnicos com o site durante a coleta de dados dos artigos da FMat.

Salientamos a importância da construção de saberes matemáticos junto a Educação Profissional Tecnológica por parte dos docentes que atuam no Ensino Profissional, ainda que sejam formados nas mais diversas áreas. É importante construir uma integração mais ativa entre o ensinar matemática e as práticas pedagógicas voltadas para o mundo do trabalho, sendo fundamental para os estudantes adquirirem a autonomia que será necessária na perspectiva do mercado de trabalho.

\section{Considerações finais}

Neste trabalho, objetivamos compreender possíveis traços característicos no perfil dos professores que atuam e ensinam matemática na Educação Profissional e Tecnológica. Em especial, investigamos a formação dos docentes, seus vínculos empregatícios, suas experiências com pesquisas de Educação Matemática na Educação Profissional Técnica de Nível Médio (EPTNM) e suas participações em grupos de pesquisa.

Com os dados obtidos, observamos que a preocupação em relação ao ensino profissionalizante está cada vez mais presente no cotidiano de docentes das mais diversas áreas do conhecimento. O levantamento de dados trouxe resultados otimistas no que tange à participação na busca de um ensino interdisciplinar e a importância da integração entre 
Deborah da Silva Pimentel, Ana Clara Frossard Souza e Lauro Chagas e Sá

Um perfil dos professores que compartilham experiências de Educação Matemática com estudantes da Educação Profissional e Tecnológica

a Matemática e as demais disciplinas para a emancipação do aluno. Entretanto, percebemos ainda existe uma lacuna a ser preenchida no que diz respeito a discussão sobre professores que ensinam Matemática. Vimos que existem muitas contribuições por parte desses profissionais, mas ainda assim são poucos citados em trabalhos acadêmicos que abordam sobre o ensino de Matemática.

Com esse artigo, evidenciamos que a prática docente da Educação Matemática na EPT não se faz somente por profissionais graduados nessa área. Assim, propomos então um alargamento ainda maior da terminologia "professores que ensinam matemática", passando de um grupo que contém matemáticos e pedagogos para um grupo que possui outras formações, e que eventualmente atuam na Educação Profissional ensinando matemática à alunos do curso técnico. Assim, esperamos contribuir com pesquisas sobre a Formação de Professores discutindo as características da formação e da atuação profissional de docentes que ensinam Matemática na EPT.

\section{Referências}

ARAÚJO, R. M. L. Formação de docentes para a Educação Profissional e Tecnológica: por uma pedagogia integradora da Educação Profissional. Trabalho \& Educação. Vol. 7. nº 2.mai/ago, 2008.

BITTENCOURT, J. Sentidos da integração curricular e o ensino de matemática nos parâmetros curriculares nacionais. Zetetiké, v. 12, n. 2, p. 71-88, 17 fev. 2009.

BRASIL. Ministério da Educação. Secretaria de Educação Profissional e Tecnológica. Centenário da Rede Federal de Educação Profissional e Tecnológica. Disponível em:

http://portal.mec.gov.br/setec/arquivos/centenario/historico_educacao_profissional.pdf

BRASIL; MINISTÉRIO DA EDUCAÇÃO. Resolução nº 6, de 20 de setembro de 2012. Define as Diretrizes Curriculares Nacionais para a Educação Profissional Técnica de Nível Médio. Disponível em:

http://portal.mec.gov.br/component/docman/?task=doc_download\&gid=11663\&Itemid

BRASIL. Lei 11.892, de 29 de Dezembro de 2008. Institui a Rede Federal de Educação Profissional, Científica e Tecnológica, cria os Institutos Federais de Educação Ciências e Tecnologia, e dá outras providências. Diário Oficial da União, Seção 1, p.1, 30/12/2008. Disponível em: http://www.planalto.gov.br/ccivil_03/_Ato2007-2010/2008/Lei/L11892.htm

FERNANDES, F. S.; VALENTE, W. R. Sociedade Brasileira de Educação Matemática, 30 anos: sujeitos, políticas e produção de conhecimento. Bolema, Rio Claro (SP), v. 33, n. 63, p. iv-xix, abr. 2019. 
FERREIRA, F. A. Provas e demonstrações: compreensões de dez anos da produção em educação matemática expressa em eventos (2003-2013). 417 f. Tese (Doutorado) Curso de Programa de Pós-graduação em Ensino de Ciências e Matemática, Universidade Cruzeiro do Sul, São Paulo, 2016.

FREITAS, I. A. F.; SÁ, L. C. e. Os bastidores de práticas interdisciplinares da Educação Profissional técnica de nível médio: o que dizem os professores que ensinam matemática?. Revista Brasileira de Ensino de Ciência e Tecnologia, Ponta Grossa, v.13, n. 1, p. 333-348, jan./abr. 2020. Disponível em: http://dx.doi.org/10.3895/rbect.v13n1.9888

FRIGOTTO, G.; CIAVATTA, M.; RAMOS, M. N. A gênese do Decreto n. 5.154/2004: um debate no contexto controverso da democracia restrita. In: (Orgs.). Ensino médio integrado: concepção e contradições. São Paulo: Cortez, p. 21-56, 2005.

Instituto Brasileiro de Geografia e Estatística (IBGE). Síntese de Indicadores Sociais uma análise das condições de vida da população brasileira 2018. Rio de Janeiro: IBGE; 2018.

MACHADO, L. R. de S. Diferenciais inovadores na formação de professores para a Educação Profissional. Revista Brasileira da Educação Profissional e Tecnológica, Brasília, v. 1, nº 1, 2008.

MOURA, D. H. Trabalho e formação docente na Educação Profissional. Coleção formação pedagógica. v.3. Curitiba, PR: IFPR -EAD. 2014. Disponível em: https://portal.ifrn.edu.br/pesquisa/editora/livros-para-download/trabalho-e-formacaodocente-na-educacao-profissional-dante-moura

PAVIANI, J. Disciplinaridade e interdisciplinaridade. In: PIMENTA, C. Interdisciplinaridade, humanismo, universidade. Porto (Portugal): Campo das Letras, 2004. p. 15-57

SKOVSMOSE, O. Um convite à educação matemática crítica. 1.ed., Campinas, SP: Papirus, 2014.

SILVA, E. S. da; OLIVEIRA, A. T. da C. C. de. O Ensino Médio Integrado sob Diferentes Perspectivas para o Ensino de Matemática. Zetetiké, v. 26, n. 2, p. 423-438, 13 jun. 2018.

Recebido em: 09 / 05 / 2021 Aprovado em: 17 / 06 / 2021 